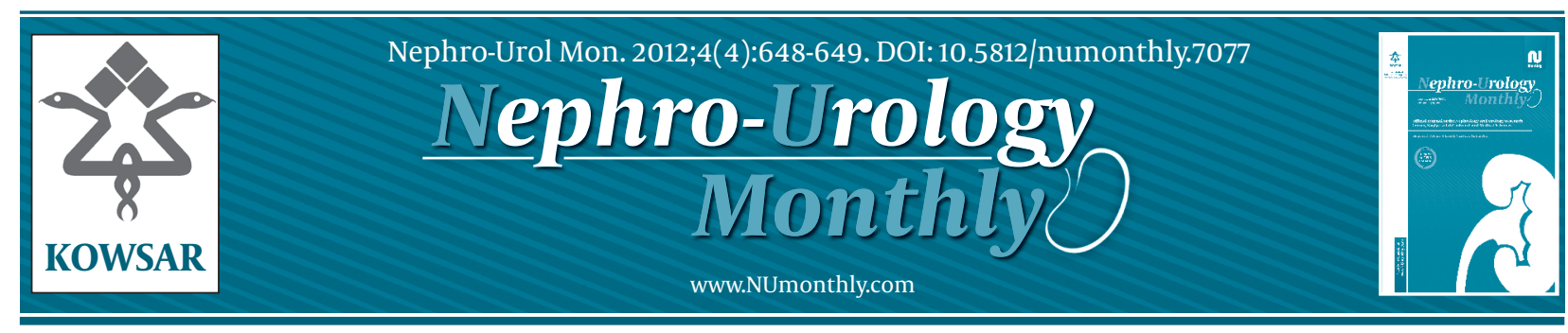

\title{
Issues of Renal Replacement Therapy in Elders Living Low-Income Afri- can Countries
}

\author{
Sidy Mohamed Seck ${ }^{1^{*}}$ \\ ${ }^{1}$ Faculty of Health Sciences, University Gaston Berger, Saint-Louis, Senegal
}

A R T I C L E I N F O

Article type:

Letter to Editor

Article history:

Received: 06 Jul 2012

Revised: 11 Jul 2012

Accepted: 17 Jul 2012

Keywords:

Renal Replacement Threrapy

Renal Dialysis

Africa South of the Sahara

\section{Dear Editor,}

We read with interest the article by Smyth A about dialysis indications and the modalities of RRT in elderly patients (1). We would herein underline the particular situation in resource limited areas like sub-Saharan Africa where dialysis access is still very poor and nephrologists have often to make a selection among the growing number of and end-stage renal disease (ESRD) patients who need dialysis (2). We recently reported a high prevalence of chronic kidney disease (CKD) (10.7\%) in black African patients aged $\geq 60$ years with more than half of them presenting ESRD and having no access to renal replacement therapy (RRT) (3). So discussing indications and dialysis methods may appear as superfluous in a context of few dialysis facilities where elderly patients are in competition with young adults and children who are more likely to take profits from dialysis treatment. In this article, authors recommend to balance short-term RRT survival benefit (hemodialysis or peritoneal dialysis) with pos-

\begin{abstract}
- Please cite this paper as:
Seck SM. Issues of Renal Replacement Therapy in Elders Living Low-Income African Countries. Nephro-Urol Mon.2012;4(4): 6489. DOI: 10.5812/numonthly.7077
\end{abstract}

Published by Kowsar Corp, 2012. cc 3.0. sible evitable co-morbidities and unnecessary medicalization (1). We agree with the general rule of proposing dialysis to all ESRD patients regardless of their age but for nephrologists working in countries with poor dialysis access, we think that conservative multidisciplinary management should be encouraged as a socio-culturally and medically efficient alternative for elders with ESRD specially if they have co-morbidities $(4,5)$. Cohort studies comparing RRT and conservative therapy in elders living resource-limited countries should be performed to precise dialysis indications in these populations.

\section{Authors' Contribution}

Sidy M Seck: design and writting the paper.

\section{Financial Disclosure}

None declared.

\footnotetext{
* Corresponding author: Sidy Mohamed Seck, Internal medicine and Nephrology Department, Faculty of Health Sciences, University Gaston Berger, Route de Ngallele, BP 234, Saint-Louis, Senegal. Tel:+221-339612356, Fax:+221-33961188, E-mail: sidy-mohamed.seck@ugb.sn
} DOI:10.5812/numonthly.7077

(C) 2012 Nephrology and Urology Research Center and Baqiyatallah University of Medical Sciences; Published by Kowsar Corp.

This is an Open Access article distributed under the terms of the Creative Commons Attribution License (http://creativecommons.org/licenses/by/3.0), which permits unrestricted use, distribution, and reproduction in any medium, provided the original work is properly cited. 


\section{References}

1. Smyth A. End-Stage Renal Disease and Renal Replacement Therapy in Older Patients. Nephro-Urol Mon. 2012;4(02):425-30.

2. Kher V. End-stage renal disease in developing countries. Kidney Int. 2002;62(1):350-62.

3. Seck SM, al. e. Epidemiological patterns of chronic kidney disease in black African elders: a retrospective study in West Africa.

Saudi J Kidney Dis Transplant. 2012. [epub a head of print]

4. Carson RC, Juszczak M, Davenport A, Burns A. Is maximum conservative management an equivalent treatment option to dialysis for elderly patients with significant comorbid disease? Clin J Am Soc Nephrol. 2009;4(10):1611-9.

5. Brown EA, Johansson L. Epidemiology and management of endstage renal disease in the elderly. Nat Rev Nephrol. 2011;7(10):591-8. 